\title{
A simple method of unclogging enteral feeding tubes: even when traditional methods have failed
}

\begin{abstract}
Hundreds of thousands of patients require enteral nutrition or hydration through feeding tubes every year in the United States of America. Unfortunately, up to 35\% of these tubes become clogged. Surgeons and interventional radiologists are often consulted to either unclog or replace them. There are several established methods of clearing clogged enteric tubes, some of which include simple saline flushing, enzyme agent administration, hot water or carbonated soda administration, wire manipulation, and mechanical unclogging devices. We demonstrate a simple and effective technique for unclogging enteric tubes, even when traditional methods are unsuccessful; thus circumventing the need for replacement, decreasing radiation exposure and healthcare costs for patients.
\end{abstract}

Keywords: enteral, unclog, tube, feeding, flush
Volume 9 Issue I - 2019

\author{
Asaph CJ Levy, Sandor Kovacs \\ Department of Radiology, Lenox Hill Hospital, USA
}

Correspondence: Asaph Levy, Department of Radiology, Lenox Hill Hospital, Northwell Health System, USA, Tel 212 434-2000,Email asaphlevy@gmail.com

Received: January 09, 2019 | Published: January 21, 2019

\section{Introduction}

Enteral feeding tubes are commonly placed as a means for providing patients with nutrition and hydration when they are unable to meet their daily caloric and hydration requirements by mouth. They may also be placed in patients who are at a significant aspiration risk. This may be secondary to malignancy, neurological or mechanical dysphagia, as well as critical illness. ${ }^{1}$ Many neurological diseases cause dysphagia, but patients with traumatic brain injury (TBI), cerebrovascular disease, degenerative central nervous system disease, and hypoxic brain injury comprise the majority of referrals in this subset of patients. ${ }^{2}$ These patients not only require enteral nutrition, but they also require medications through these tubes. Medications are preferably administered in liquid form. However, there are several medications that are only manufactured in solid form. These medications require being crushed and dissolved in water prior to administration through feeding tubes.

Although feeding tubes can be very helpful, they often become obstructed. Clotting of intact protein formulas and crushed medications are thought to be the most common etiologies of clogged feeding tubes. ${ }^{3}$ However, there is a lack of data to definitively support this theory. Other etiologies include refluxed gastric contents, viscous products, and precipitated protein products. A clear-cut etiology is unknown for the majority of cases.

According to the American Society for Enteral and Parenteral Nutrition (ASPEN) data from 2009, more than 245,000 patients per year require at least a temporary feeding tube during a hospital stay. Approximately 31,000 patients require enteral nutrition at home per year. ${ }^{4}$ It is estimated that up to $35 \%$ of enteral tubes become clogged. ${ }^{3,5}$ We are often consulted to unclog or replace these enteric tubes. This may expose patients and interventionalists to additional radiation and increased healthcare costs.

Prevention of enteric tube clogs is ideal. Recommendations for clog prevention include adequate and frequent flushing, administration of thoroughly crushed and dissolved medications preceded and followed by water/saline flushing, limiting residual checks, avoiding mixing medications together prior to administration, and avoiding administration of acidic liquids through the enteric tube. ${ }^{5,6}$ The most effective method of preventing enteral feeding tube clogging is frequent flushing. ${ }^{7,8}$ Water is reported to be preferred for flushing, as saline can crystallize within the tube. ${ }^{9}$

There are several methods for unclogging enteral feeding tubes. The most common methods include: warm/hot saline flushing, administration of enzymatic agents, mechanical devices such as the Tube Clear System (Actuated Medical, Bellefonte, PA, U.S.A), wire manipulation, as well as administration of cola, meat tenderizers, and

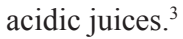

The TubeClear system can be used on nasogastric, gastric, and jejunostomy tubes sized 10-18 French. It involves a stem paired with a control box that is plugged into $\mathrm{AC}$ power to produce a jackhammerlike motion to clear tube obstructions. The downside to this system is that it is a costly option and carries a small but increased risk of tube perforation. We demonstrate a simple and effective alternative technique.

\section{Case report}

A few items are required for this technique. These items are as follows: 18-gauge needle (Smiths Medical, Dublin, OH, U.S.A) (preferably a blunt tip Luer Lock needle) or stiff catheter, a curved or straight Kelley clamp (Cardinal Health, Dublin, OH, U.S.A), and a normal saline flush (BD, Franklin Lakes, NJ, U.S.A) (Figure 1). This technique comprises of a few simple steps. The first step is to insert the 18-gauge needle or stiff catheter into the feeding tube, taking care not to perforate the wall of the tube, if using a sharp tip needle (Figure $2 a)$. The next step is to apply the Kelley clamp around the feeding tube and on top of the needle, such that the tube is completely collapsed around the patent needle (Figure 2b). Then attach a saline flush syringe to the needle and start injecting gently to feel for resistance (Figure 3a). Once resistance is felt, apply a gradual increase in pressure until the resistance is relieved and saline flows freely through the opposite end of the tube (Figure 3b). At times it may be necessary to agitate the saline within the tube to clear the obstruction, which can be achieved by rapidly alternating gentle injection and release of pressure. It is important to stabilize the needle and tube in one hand and inject with the other in order to prevent puncture of the tube. Once the resistance is cleared, an additional water or saline flush can be used to flush the tube, after unclamping and removing the needle from the tube. 


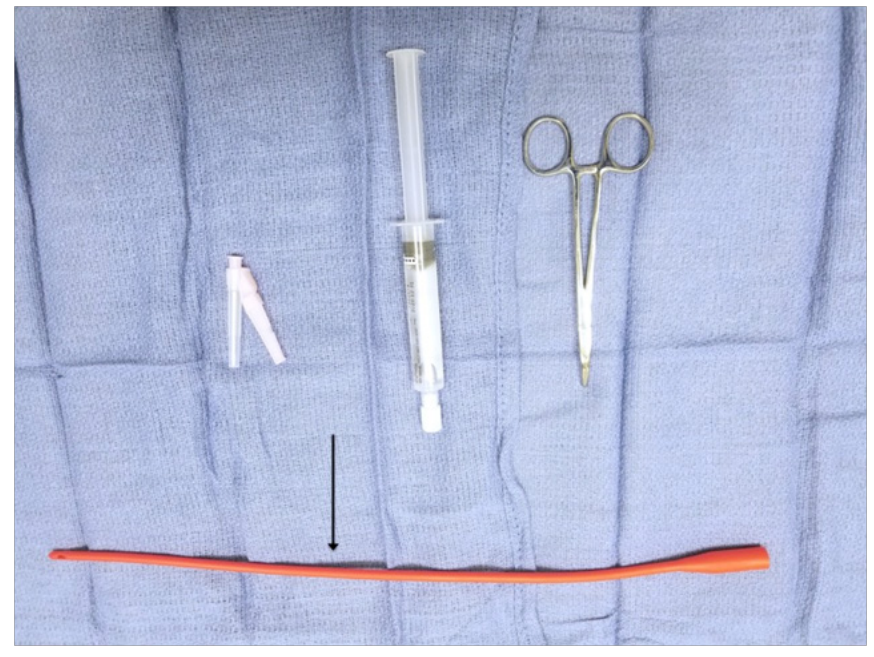

Figure I Items needed for our technique are (from left to right): an I8-gauge needle (preferably a blunt tip Luer Lock needle), a saline flush, and a curved Kelley clamp.A I6French red rubber catheter is also depicted (black arrow).

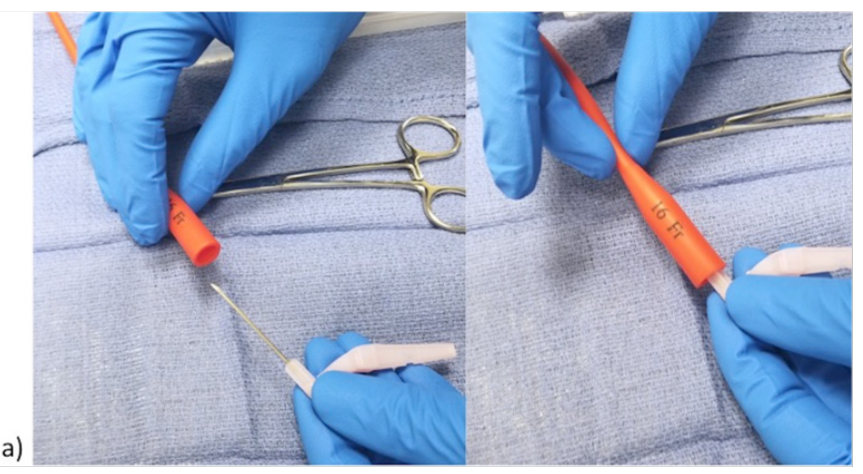

Figure $2 \mathrm{a}$ The first step is to insert the needle into the feeding tube, taking care not to puncture the wall of the tube.

b)

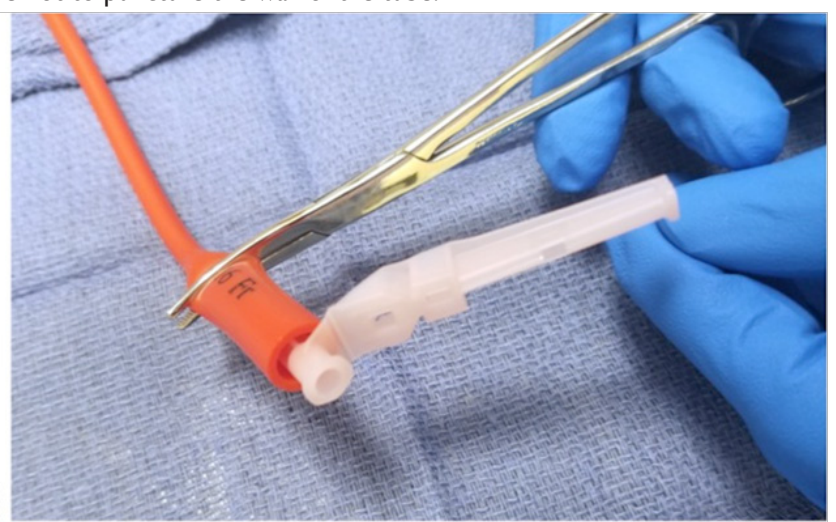

Figure $\mathbf{2 b}$ The next step is to apply the Kelley clamp around the feeding tube, such that the tube is completely collapsed around the patent needle.

Eleven patients with clogged feeding jejunostomy tubes, all thought to be secondary to medication/protein precipitate, were brought to our attention for either unclogging or replacement during a 1 year period. Eight of the feeding tubes were composed of red rubber latex and three were composed of silicone. The feeding tubes were reported to be occluded between 0 and 2 days prior to attempted unclogging with this technique (mean of 0.9 days). Other techniques such as wire instrumentation, hot water and carbonated soda administration, simple saline flushing, and administration of an enzyme declogging agent were unsuccessful in most of these patients. Mechanical devices such as TubeClear were not utilized on these patients.
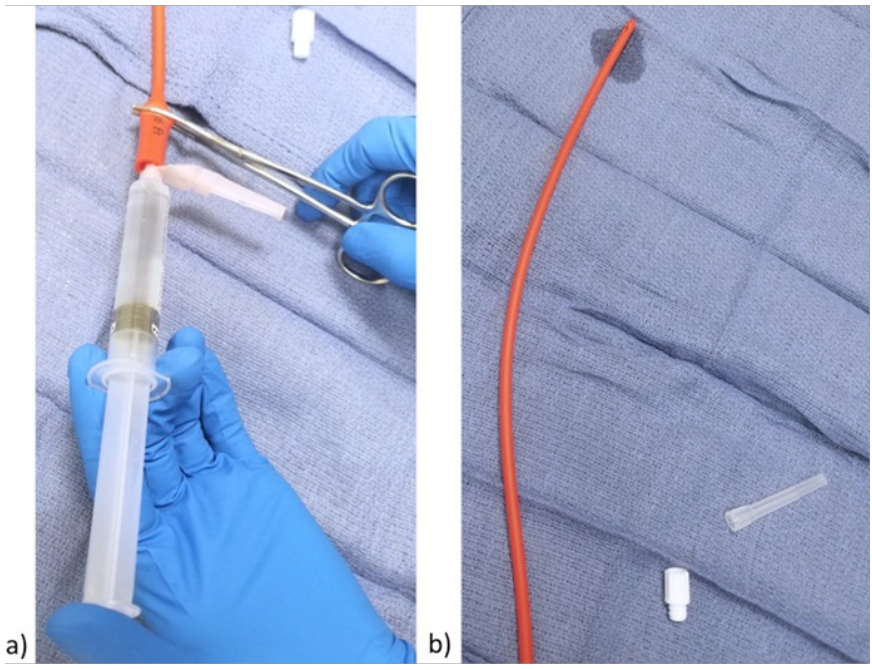

Figure 3 (a) Attach the saline flush to the needle and gradually inject saline while feeling for resistance. (b) Once resistance is appreciated, apply a gradual increase in pressure until the resistance is relieved and saline flows freely through the opposite end of the tube.

Approximately $91 \%$ of jejunostomy tubes were successfully unclogged with this technique. It was the initial unclogging method attempted on 4 patients. However, the remaining 7 patients received traditional techniques that were unsuccessful prior to the utilization of this technique.

The time to unclog using this technique ranged between 2 and 8 minutes, with a mean time of 4.6 minutes per successful application. See Table 1 for detailed results for each patient.

\section{Discussion}

This technique allows for a significant amount of pressure to be applied without allowing saline to reflux back out of the feeding tube. This increase in pressure is typically adequate to relieve most obstructions. It was successful in clearing $91 \%$ of clogged enteral tubes; this includes 7 enteric tubes on which one or multiple other techniques were previously unsuccessful. However, there was 1 enteric tube that was unsuccessfully unclogged with this technique. This was secondary to a hole in the tube proximal to the clamp. Saline leaked through this defect during injection, thus precluding the ability to generate an adequate amount of pressure to clear the obstruction. This jejunostomy tube was eventually replaced. Although every patient in this study had jejunostomy tubes, this technique is applicable to all enteral feeding tubes with a collapsible lumen.

In a study of 90 patients with 8 French enteric Dobbhoff tubes, Marcuard et al demonstrate 32 patients develop tube occlusions. Of these patients, activated pancreatic enzyme administration was successful in clearing $72 \%$ of occlusions. ${ }^{3}$

Mechanical devices such as TubeClear were not utilized in this study. Therefore, we are unable to prove that mechanical devices would not have been successful in unclogging these enteric tubes. However, we can deduce that this technique is a more cost effective 
alternative. To our knowledge, there are no current published studies to prove the efficacy of the TubeClear system. However, there is an ongoing clinical trial at Children's Hospital of Philadelphia to determine its efficacy in pediatric ICU patients (Clinicaltrials.gov Identifier: NCT02724631).
It is important to note that the reported time of occlusion did not exceed 2 days. Thus we cannot attest to the efficacy of this technique on tubes that are clogged for a longer period of time. However, since patients are typically dependent on feeding tubes for nutrition and hydration, tube obstructions are typically discovered within the first 24 hours.

Table I Summary of cases and outcomes

\begin{tabular}{|c|c|c|c|c|c|c|}
\hline Patient & $\begin{array}{l}\text { Type of feeding } \\
\text { tube }\end{array}$ & $\begin{array}{l}\text { Reported } \\
\text { time of } \\
\text { occlusion } \\
\text { (days) }\end{array}$ & $\begin{array}{l}\text { Suspected reason for } \\
\text { occlusion }\end{array}$ & $\begin{array}{l}\text { Unsuccessful attempted } \\
\text { techniques }\end{array}$ & $\begin{array}{l}\text { Successful } \\
\text { unclogging } \\
\text { with our } \\
\text { technique }\end{array}$ & $\begin{array}{l}\text { Time to unclog } \\
\text { in minutes with } \\
\text { our technique }\end{array}$ \\
\hline I & Red Rubber Latex & $0 *$ & Medication/Protein Precipitate & $\begin{array}{l}\text { Wire instrumentation \& Hot/ } \\
\text { Warm Water }\end{array}$ & Yes & 5 \\
\hline 2 & Silicone & I & Medication/Protein Precipitate & $\begin{array}{l}\text { Wire instrumentation, Hot /Warm } \\
\text { Water, \& Carbonated Liquids }\end{array}$ & Yes & 6 \\
\hline 3 & Red Rubber Latex & I & Medication/Protein Precipitate & No prior attempts & Yes & 2 \\
\hline 4 & Red Rubber Latex & 0 & Medication/Protein Precipitate & Simple Saline Flush & Yes & 8 \\
\hline 5 & Silicone & I & Medication/Protein Precipitate & No prior attempts & No & --- \\
\hline 6 & Red Rubber Latex & 2 & Medication/Protein Precipitate & Simple Saline Flush & Yes & 5 \\
\hline 7 & Silicone & 2 & Medication/Protein Precipitate & $\begin{array}{l}\text { Wire instrumentation \& Enzyme } \\
\text { declogging agent }\end{array}$ & Yes & 4 \\
\hline 8 & Red Rubber Latex & I & Medication/Protein Precipitate & No prior attempts & Yes & 4 \\
\hline 9 & Red Rubber Latex & I & Medication/Protein Precipitate & No prior attempts & Yes & 2 \\
\hline 10 & Red Rubber Latex & I & Medication/Protein Precipitate & $\begin{array}{l}\text { Enzyme declogging agent \& Hot } \\
\text { Water }\end{array}$ & Yes & 7 \\
\hline II & Red Rubber Latex & 0 & Medication/Protein Precipitate & $\begin{array}{l}\text { Wire instrumentation, Hot/Warm } \\
\text { Water, \& Carbonated Liquids }\end{array}$ & Yes & 3 \\
\hline
\end{tabular}

*0 days represents less than 24 hours of occlusion.

No known complications arose as a sequela of this technique. Applying too much pressure is unlikely to dislodge a jejunostomy tube, as there is typically several inches within the bowel lumen, as well as anchoring sutures in the case of surgically implanted jejunostomy tubes. Other feeding tubes may have a balloon securing it in place, as is the case for Percutaneous Gastrostomy (PEG) tubes. However, it is possible that applying too much pressure may forcefully expel the obstructing material if it is impacted, which could theoretically result in bowel injury. However, given that most obstructions are discovered within the first 24 hours, this complication is less likely if this technique is applied in a timely manner. It is important to only use as much force as needed to relieve the obstruction, this will also mitigate the risk of this complication, as well as potential tube rupture.

In lieu of our small sample size of 11 patients, more data is needed to support the efficacy and reliability of the technique. However, to our knowledge, there are no published studies describing a method for effectively increasing hydrostatic pressure to clear feeding tube obstructions.

We should strive to prevent enteric tube obstructions, although, it is oftentimes inevitable. When it occurs, the use of this technique may be a cost effective and time efficient method of circumventing the need for tube replacement. There is currently a gap in healthcare provider knowledge when it comes to best practices for unclogging feeding tubes. We present an effective option with the intent of bridging this gap.

\section{Acknowledgments}

None.

\section{Conflicts of interest}

The author declares no conflicts of interest.

\section{References}

1. Blumenstein I, Shastri YM, Stein J. Gastroenteric tube feeding: Techniques, problems and solutions. World $J$ Gastroenterol. 2014;20(26):8505-8524.

2. Lyon SM, Pascoe DM. Percutaneous Gastrostomy and Gastrojejunostomy. Semin Intervent Radiol. 2004;21(3):181-189.

3. Marcuard SP, Stegall KS. Unclogging feeding tubes with pancreatic enzyme. JPEN J Parenter Enteral Nutr. 1990;14(2):198-200.

4. Fisher C, Blalock B. Clogged Feeding Tubes: A Clinician's Thorn. Nutrition Issues in Gastroenterology, Series.127, 2014;38(3): 16-22.

5. Garrison CM. Enteral Feeding Tube Clogging: What Are The Causes and What Are the Answers? A Bench Top Analysis. Nutr Clin Pract. 2018;33(1):147-150.

6. Grissinger M. Preventing Errors When Drugs Are Given Via Enteral Feeding Tubes. P T 2013;38(10):575-576.

7. Hayes KD, Hayes DD. Best Practices for unclogging feeding tubes in adults. Nursing. 2018;48(6):66.

8. Dandeles LM, Lodolce AE. Efficacy of Agents to Prevent and Treat Enteral Feeding Tube Clogs. Ann Pharmacother. 2011;45(5):676-680.

9. Schrag SP, Sharma R, Nikhil PJ, et al. Complications Related to Percutaneous Endoscopic Gastrostomy (PEG) Tubes. A Comprehensive Clinical Review. J Gastrointestin Liever Dis. 2007;16(4):407-418. 